Marquette University

e-Publications@Marquette

College of Education Faculty Research and

Publications

Education, College of

2019

\title{
A Psychometric Analysis of the Social Anxiety Scale for Adolescents Among Youth with Autism Spectrum Disorder: Caregiver-Adolescent Agreement, Factor Structure, and Validity
}

Hillary Schiltz

Marquette University

Brooke E. Magnus

Marquette University, brooke.magnus@bc.edu

Alana J. McVey

Marquette University

Angela Haendel

Marquette University

Bridget Dolan

Marquette University, bridget.dolan@marquette.edu

See next page for additional authors

Follow this and additional works at: https://epublications.marquette.edu/edu_fac

Part of the Education Commons

\section{Recommended Citation}

Schiltz, Hillary; Magnus, Brooke E.; McVey, Alana J.; Haendel, Angela; Dolan, Bridget; Stanley, Rachel E.; Willar, Kirsten S.; Pleiss, Sheryl; Carson, Audrey Meyer; Carlson, Mary E.; Murphy, Christina; Vogt, Elisabeth M.; Yund, Brianna D.; and Van Hecke, Amy V., "A Psychometric Analysis of the Social Anxiety Scale for Adolescents Among Youth with Autism Spectrum Disorder: Caregiver-Adolescent Agreement, Factor Structure, and Validity" (2019). College of Education Faculty Research and Publications. 537.

https://epublications.marquette.edu/edu_fac/537 


\section{Authors}

Hillary Schiltz, Brooke E. Magnus, Alana J. McVey, Angela Haendel, Bridget Dolan, Rachel E. Stanley, Kirsten S. Willar, Sheryl Pleiss, Audrey Meyer Carson, Mary E. Carlson, Christina Murphy, Elisabeth M. Vogt, Brianna D. Yund, and Amy V. Van Hecke 
Marquette University

e-Publications@Marquette

\section{Education Faculty Research and Publications/College of Education}

This paper is NOT THE PUBLISHED VERSION; but the author's final, peer-reviewed manuscript. The published version may be accessed by following the link in the citation below.

Assessment, (2019). DOI. This article is (C) SAGE Publications and permission has been granted for this version to appear in e-Publications@Marquette. SAGE Publications does not grant permission for this article to be further copied/distributed or hosted elsewhere without the express permission from SAGE Publications.

\section{A Psychometric Analysis of the Social Anxiety Scale for Adolescents Among Youth with Autism Spectrum Disorder: Caregiver- Adolescent Agreement, Factor Structure, and Validity}

Hillary K. Schiltz

Marquette University, Milwaukee, WI

Brooke E. Magnus

Marquette University, Milwaukee, WI

Alana J. McVey

Marquette University, Milwaukee, WI

Angela D. Haendel

Marquette University, Milwaukee, WI

Bridget K. Dolan

Medical College of Wisconsin, Milwaukee, WI 


\section{Rachel E. Stanley}

Marquette University, Milwaukee, WI

Kirsten A. Willar

Stanford Children's Health, Palo Alto, CA

Sheryl J. Pleiss

Great Lakes Neurobehavioral Center, Edina, MN

Audrey M. Carson

Baylor College of Medicine, Houston, TX

Mary Carlson

Marquette University, Milwaukee, WI

Christina Murphy

Marquette University, Milwaukee, W

Elisabeth M. Vogt

Marquette University, Milwaukee, W

Brianna D. Yund

University of Wisconsin-Milwaukee, Milwaukee, WI

Amy Vaughan Van Hecke

Marquette University, Milwaukee, WI

\section{Abstract}

Social anxiety is common among adolescents with autism spectrum disorder (ASD). An ongoing challenge for both research and clinical practice in ASD is the assessment of anxious symptomatology. Despite its widespread use in samples of youth with ASD, the Social Anxiety Scale for Adolescents (SASA) has not received psychometric evaluation within this population; thus, the validity of its use in research and clinical practice for ASD remains unclear. The present study conducted a psychometric analysis of caregiver and adolescent SAS-A forms in a sample of adolescents with ASD $(N=197)$. Results revealed (1) poor caregiver-adolescent item-level agreement, (2) a two-factor structure, (3) lack of measurement invariance between reporters, and (4) modest evidence for convergent and discriminant validity. Overall, findings suggest that this measure demonstrates reasonable psychometric properties in an ASD sample. Lack of measurement invariance, however, calls for careful interpretation of research involving the SAS-A in ASD samples, particularly when the primary goal is to compare adolescent and caregiver reports. The implications of these findings for future research and clinical practice are discussed.

\section{Keywords}

autism spectrum disorder, social anxiety, parent-child agreement, factor structure, measurement invariance, validity

Autism spectrum disorder (ASD) is a lifelong neurodevelopmental disorder that affects approximately 1 in 45 youth (Zablotsky, Black, Maenner, Schieve, \& Blumberg, 2015). Autism is characterized by challenges in social communication as well as restricted and/or repetitive behaviors (American 
Psychiatric Association, 2013) and is often accompanied by additional co-occurring internalizing or externalizing symptoms (Leyfer et al., 2006). Symptoms of social anxiety, in particular, are common and thought to amplify core symptoms of ASD (Bellini, 2006; Duvekot, Ende, Verhulst, \& Greaves-Lord, 2017) and, thus, merit the attention of basic and applied researchers alike. Issues surrounding assessment of social anxiety in ASD likely limit progress in this line of work; parent-child agreement concerns are compounded with the dearth of anxiety measures that have received psychometric evaluation within this population. The Social Anxiety Scale for Adolescents (SAS-A) is a questionnaire commonly used to assess symptoms of social anxiety and may be a useful tool for research and clinical practice related to ASD. To the authors' knowledge, however, no study to date has conducted a thorough psychometric evaluation of the SAS-A in an ASD sample nor examined whether the adolescent and caregiver reports have similar psychometric properties. These, therefore, are the goals of the present study.

\section{Social Anxiety and Autism Spectrum Disorder}

Co-occurring symptoms of anxiety and, more specifically social anxiety, commonly engender additional challenges that extend beyond autism alone. Evidence suggests that many youth with ASD experience clinical levels of social anxiety (van Steensel, Bögels, \& Perrin, 2011; White, Oswald, Ollendick, \& Scahill, 2009), with a recent meta-analysis indicating higher levels of anxiety in youth with ASD compared with typically developing youth (van Steensel \& Heeman, 2017). Symptoms of social anxiety and autism are likely intimately intertwined -White, Bray, and Ollendick (2012) identified two highly correlated, yet separate, factors for social anxiety and social difficulties. Thus, social anxiety is conceptualized as a set of distinct, yet highly enmeshed, co-occurring symptoms that may exacerbate and be exacerbated by social challenges for those with ASD (Bellini, 2006; Chang, Quan, \& Wood, 2012). Social anxiety in autism is hypothesized to stem from a combination of physiological symptoms, social withdrawal, underdeveloped social skills, and unsuccessful social interactions (Bellini, 2006) which may, in turn, further perpetuate social rejection and, thus, beget greater levels of anxiety symptoms (Duvekot et al., 2017; Factor, Ryan, Farley, Ollendick, \& Scarpa, 2017; Wood \& Gadow, 2010).

\section{Assessing Social Anxiety in Autism Spectrum Disorder}

Although the understanding of anxiety in ASD is burgeoning, a pressing challenge for research in this area is accurate assessment of anxious symptoms among those with ASD. Such difficulties are, in part, rooted in concern regarding caregiver-child agreement and, thus, potentially accuracy and reliability of the reporter (Blakeley-Smith, Reaven, Ridge, \& Hepburn, 2012; Mazefsky, Kao, \& Oswald, 2011; White, Schry, \& Maddox, 2012). While poor agreement is often attributed to inaccuracies on the part of either the parent or child, differences in measurement properties could also contribute to the emergence of disagreement (Olino, Finsaas, Dougherty, \& Klein, 2018), yet is not often explored. Beyond these issues, a second major concern is the lack of psychometrically sound measurement tools to assess for social anxiety in ASD (e.g., Jitlina et al., 2017; White, Lerner, et al., 2015).

Research suggests that parents and their children often differ in their reports of child psychopathology (e.g., De Los Reyes \& Kazdin, 2005) and this process may be at play to an even greater extent in ASD. More specifically, evidence from item-level analyses raises concerns regarding parent-child agreement 
on measures of anxiety in ASD. For example, analyses of the Screen for Child Anxiety Related Emotional Disorders in Children (Birmaher et al., 1997) have suggested poor item-level agreement between parent and child reports (Blakeley-Smith et al., 2012). Similarly, across items on the Spence Children's Anxiety Scale (Spence, 1998), parent-child agreement has been found to widely vary (Magiati, Chan, Tan, \& Poon, 2014). For the social phobia items of the Spence Children's Anxiety Scale specifically, agreement was found to be poor, with the exception of items reflecting fear of using public toilets ( $\rho=.57$ ) and fear of taking tests ( $\rho=.37$; Magiati et al., 2014). Additional concerns have been raised in the examination of anxiety measures at the scale and subscale levels; there has been some empirical investigation of reporter (caregiver vs. child) discrepancies of anxiety in ASD, yet findings in the literature are mixed. Some suggest that parents report higher anxiety levels (Lopata et al., 2010), lower anxiety levels (Hurtig et al., 2009; Ooi et al., 2016; White, Schry, et al., 2012), and the same mean anxiety level (Burrows et al., 2018; May, Cornish, \& Rinehart, 2015) compared with their child with ASD.

Given that poor parent-child agreement and mean-level discrepancies are commonly reported in the literature on ASD, careful consideration of possible factors contributing to disagreement, namely barriers to accurate reporting of behalf of the child and parent (Stratis \& Lecavalier, 2015), as well as psychometric sources of disagreement (Olino et al., 2018) are essential. Caution is advised when utilizing self-report measures in ASD (Mazefsky et al., 2011), likely due to possible limitations in introspection (Williams, 2010) and emotion identification (Uljarević \& Hamilton, 2013) among youth with ASD. In light of these concerns, parent report is often employed as a proxy. Parent report, however, is inherently limited, especially for internalizing symptoms; evidence broadly points to greater disagreement for less observable symptoms in youth (Comer \& Kendall, 2004; Ooi et al., 2016).

An important and often overlooked limitation in this line of research is the assumption of measurement invariance between parent and child; measurement invariance is a critical prerequisite for the examination of mean-level informant discrepancies, and may also contribute to item-level disagreement (Olino et al., 2018). Without evidence to support measurement invariance between reporters, it is possible that discrepancy findings and poor agreement may be due to differences in how the instrument functions between the two groups rather than true differences in the underlying construct. Thus, to make valid inferences about mean-level differences in anxiety at the scale level and to explore possible contributors to poor agreement, measurement invariance should be investigated.

Other hindrances in this line of work are attributable to the paucity of anxiety measures that have received psychometric evaluation with an ASD sample (e.g., Jitlina et al., 2017; Kerns et al., 2016; Schiltz, McIntyre, Swain-Lerro, Zajic, \& Mundy, 2017; Uljarević et al., 2017; White, Lerner, et al., 2015) or the dearth of measures developed specifically for use in ASD (e.g., Kerns, Renno, Kendall, Wood, \& Storch, 2017; Rodgers et al., 2016). While some anxiety measures have support for their use in research on ASD (Rodgers et al., 2016; Schiltz et al., 2017; White, Lerner, et al., 2015), evidence suggests that others may not be appropriate without adaptations (Jitlina et al., 2017).

Moreover, measures with empirical support for use in ASD assess anxiety disorders broadly and, thus, tend to include only one social anxiety subscale (e.g., the Multidimensional Anxiety Scale for Children; March, 2013). To the authors' knowledge, no measures tapping into social anxiety specifically have received comprehensive psychometric evaluation within the ASD literature. Literature on social 
anxiety among typically developing youth suggests that social anxiety is a multidimensional construct, with factors that differentiate between social interaction and performance anxiety (Watson \& Friend, 1969). While the SAS-A captures the multidimensional structure of social anxiety within typically developing clinical populations, it is unknown whether the questionnaire measures the same constructs within an ASD sample. Furthermore, it is unclear how the constructs assessed by the SAS-A correlate with constructs that are commonly studied in ASD samples (i.e., convergent and discriminant validity).

\section{The Social Anxiety Scale for Adolescents}

The SAS-A (La Greca \& Lopez, 1998) has been widely used in studies of typically developing adolescents to assess a range of symptoms associated with social anxiety. This measure is the product of a series of iterations of the Social Anxiety Scale for Children (SASC; La Greca, Dandes, Wick, Shaw, \& Stone, 1988), which was based on a measure designed for adults (Watson \& Friend, 1969). The SASC includes 10 items that load onto two factors, fear of negative evaluation (FNE, 6 items) and social avoidance and distress (SAD, 4 items). The SASC was subsequently revised to include eight new items and was found to have a three-factor structure (SASC-R; La Greca \& Stone, 1993). Two separate SAD factors emerged: SAD specific to new situations or peers (SAD-N) and more pervasive social distress (SAD-G). Finally, the SAS-A is an upward developmental extension of the SASC-R; this version was created with linguistic alterations to ensure items were developmentally appropriate for adolescents. Evidence suggests strong psychometric properties for the SAS-A among typically developing adolescents (La Greca \& Lopez, 1998). In parallel with the SASC-R, the SAS-A was found to have a three-factor structure involving FNE, SAD-G, and SAD-N. Several researchers have replicated the three-factor structure of the SAS-A in English (Inderbitzen-Nolan \& Walters, 2000; Storch, Masia-Warner, Dent, Roberti, \& Fisher, 2004) and Spanish (García-López, Olivares, Hidalgo, Beidel, \& Turner, 2001). Another study similarly identified a three-factor structure and additionally suggested eliminating five items due to crossloadings or weak loadings (Q1, Q5, Q8, Q18, Q19; Myers, Stein, \& Aarons, 2002).

The SAS (both the SASC-R and SAS-A) has been widely used in studies of children and adolescents with ASD to answer a multitude of research questions; use of the SAS in these studies is briefly reviewed here. Studies have employed the SAS to examine rates of social anxiety in ASD (Bellini, 2004), differences in social anxiety between typically developing and ASD samples (Burnette et al., 2005; Kuusikko et al., 2008), predictors of social anxiety (Bellini, 2006; Swain, Scarpa, White, \& Laugeson, 2015; Ung et al., 2016; Usher, Burrows, Schwartz, \& Henderson, 2015), neurological correlates of social anxiety (Burnette et al., 2005; Henderson et al., 2006; McPartland et al., 2012; Sutton et al., 2005), outcomes of interventions (Kaboski et al., 2015; Laugeson, Ellingsen, Tucci, Bolourian, \& Bates, 2015), and predictors of parent-child discrepancies (Burrows et al., 2018). Of these studies, many examined the SAS at the subscale level (Bellini, 2004; Burnette et al., 2005; Henderson et al., 2006; Kaboski et al., 2015; Kuusikko et al., 2008; McPartland et al., 2012; Meyer, Mundy, Van Hecke, \& Durocher, 2006; Sutton et al., 2005; Swain et al., 2015; Ung et al., 2016), while some studies used the total score (Bellini, 2006; Burrows et al., 2018; Laugeson et al., 2015; Usher et al., 2015). Studies have used both the adolescent version for older youth (Bellini, 2004, 2006; Laugeson et al., 2015; Swain et al., 2015) as well as the child version (Burnette et al., 2005; Burrows et al., 2018; Henderson et al., 2006; Kaboski et al., 2015; Kuusikko et al., 2008; McPartland et al., 
2012; Meyer et al., 2006; Sutton et al., 2005; Ung et al., 2016; Usher et al., 2015). One study examined the SASC-R with the original items, as well as a revised version excluding items that the authors suspected would be too closely related to ASD symptoms; findings appeared similar for both versions (Kuusikko et al., 2008). Only two studies used both parent and child versions (Laugeson et al., 2015; Swain et al., 2015). Together, findings from these studies have been used to draw many conclusions: social skills have been linked with symptoms of social anxiety (Bellini, 2004, 2006), neurobiological correlates of social anxiety have been suggested (Burnette et al., 2005; Henderson et al., 2006; McPartland et al., 2012; Sutton et al., 2005), and symptoms of social anxiety have been shown to be highly prevalent in ASD (Bellini, 2004; Burnette et al., 2005; Kuusikko et al., 2008).

\section{Study Aims}

In light of the gaps in the current literature, the present study sought to conduct a psychometric analysis of caregiver and adolescent report on the SAS-A in ASD. More specifically, the current study aimed to (1) examine caregiver-adolescent item-level agreement, (2) evaluate the factor structure, (3) test measurement invariance between caregiver and adolescent forms, and (4) investigate convergent and discriminant validity of the SAS-A in a sample of adolescents with ASD.

\section{Method}

\section{Participants}

In this study, 197 adolescents with ASD and their caregivers completed the measures used in this study as part of a larger randomized controlled trial (RCT) of the Program for the Education and Enrichment of Relational Skills (PEERS ${ }^{\circledR}$; Laugeson, Frankel, Gantman, Dillon, \& Mogil, 2012) at a midsized Midwestern university. Adolescents met criteria for ASD on the Autism Diagnostic Observation Schedule-Generic (ADOS-G; total score $\geq 7$; Lord et al., 2001). Sample characteristics are presented in Table 1. For complete inclusion criteria and recruitment procedures, see Schohl et al. (2014).

Table 1. Sample Characteristics.

\begin{tabular}{|l|l|l|}
\hline & $M(S D)$ & Range \\
\hline Age & $13.40(1.46)$ & $11-16$ \\
\hline Composite IQ & $101.70(18.65)$ & $63-144$ \\
\hline ADOS-G total & $11.82(3.92)$ & $7-24$ \\
\hline Gender, \% & & \\
\hline Male & 85.2 & \\
\hline Female & 14.8 & \\
\hline Race, \% & & \\
\hline White & 81.1 & \\
\hline Asian & 4.1 & \\
\hline Black & 5.6 & \\
\hline Biracial & 4.6 & \\
\hline Not reported & 4.6 & \\
\hline Ethnicity, \% & & \\
\hline Non-Latinx & 88.8 & \\
\hline Latinx & 11.2 & \\
\hline
\end{tabular}




\begin{tabular}{|c|l|l|}
\hline Household income (\$), \% & & \\
\hline$<25,000$ & 8.7 & \\
\hline $25,000-50,000$ & 8.2 & \\
\hline $50,000-75,000$ & 18.4 & \\
\hline $75,000-100,000$ & 19.4 & \\
\hline$>100,000$ & 40.3 & \\
\hline
\end{tabular}

Note. ADOS-G = Autism Diagnostic Observation Schedule-Generic.

Composite IQ as measured by the Kaufman Brief Intelligence Test-Second edition.

\section{Procedure}

The Institutional Review Board at Marquette University approved the larger RCT. Informed consent was provided by a parent or legal guardian (henceforth "caregiver") and informed assent was given by adolescents for participation in the RCT. Adolescents and their caregivers attended a research appointment wherein they completed demographic forms and a battery of measures assessing social functioning and behavioral and emotional symptoms. Caregivers and adolescents each completed measures independently; assistance was provided to adolescents by research assistants in the lab if needed and/or on request. Adolescents were administered the Kaufman Brief Intelligence Test-Second edition (Kaufman \& Kaufman, 2004) and the ADOS-G (Lord et al., 2001). The ADOS-G was administered by research assistants trained to research reliability within the lab.

\section{Measures}

The SAS-A (La Greca \& Lopez, 1998) is an 18-item measure of social anxiety based on the SASC (La Greca et al., 1988; La Greca \& Stone, 1993). While there are totally 22 items on the measure, only 18 of these are intended to assess anxious symptoms, and 4 are unrelated to anxiety (e.g., "My child likes to read"). There are parallel caregiver- and adolescent-report versions of the SAS-A-both were administered in the present study. Caregivers and adolescents responded to each item using a 5-point Likert-type scale to indicate how much each item was true for their adolescent or themselves from 1 (not at all) to 5 (all of the time), with higher scores indicating greater levels of social anxiety. Sample items from each subscale include, "My child worries/I worry that others don't like him/her/me" (FNE), "My child gets/I get nervous when he/she meets/I meet new people" (SAD-N), and "My child is/I am quiet when he/she is/I am with a group of people" (SAD-G).

The Social Interaction Anxiety Scale (SIAS; Mattick \& Clarke, 1998) is a self-report measure consisting of 20 items related to anxiety during social interactions. Adolescents responded to each item using a 5 point Likert-type scale from 0 (not at all characteristic of me) to 4 (extremely characteristic of me). Higher scores on the SIAS indicate greater levels of social anxiety. The SIAS has been found to have acceptable psychometric properties (Brown et al., 1997; Rodebaugh, Woods, Heimberg, Liebowitz, \& Schneier, 2006) and has previously been used in ASD research (e.g., Pugliese, Fritz, \& White, 2015; White, Scarpa, Conner, Maddox, \& Bonete, 2015). A sample item from the SIAS is "I have difficulty talking with other people." Internal consistency for the present study was good ( $\alpha=.87$ ).

The Short Mood and Feelings Questionnaire (SMFQ; Angold, Costello, Messer, \& Pickles, 1995) is a 13item measure that assesses depressive symptoms and was derived from the Mood and Feelings Questionnaire (Costello \& Angold, 1988). Participants indicated whether statements were not true, 
sometimes true, or true most of the time. The SMFQ has parallel caregiver- and self-report versions; both versions were used in the present study. The SMFQ has been found to have good validity (Angold et al., 1995; Kent, Vostanis, \& Feehan, 1997; Sharp, Goodyer, \& Croudace, 2006; Thapar \& McGuffin, 1998) and has previously been used in research on ASD (e.g., Patel, Day, Jones, \& Mazefsky, 2017; White, Schry, et al., 2012). A sample item from the SMFQ is "My child/I felt miserable or unhappy." Internal consistency for the present study was excellent for caregiver report $(\alpha=.91)$ and good for adolescent report $(\alpha=.87)$.

The Social Responsiveness Scale (SRS; Constantino \& Gruber, 2005) is a commonly used 65-item measure assessing autism symptomatology. Caregivers responded to each item on a 4-point Likerttype scale from 0 (not true) to 3 (almost always true), where higher scores indicate greater ASD symptom severity. The SRS produces a total score and five subscale scores including Social Awareness, Social Communication, Social Cognition, Social Motivation, and Autistic Mannerisms; only the total score was used in the present study. The SRS has been found to have good reliability and validity (Constantino et al., 2003). Internal consistency on the SRS total score for the present study was excellent $(\alpha=.92)$.

\section{Data Analysis Plan}

\section{Item-Level Descriptive Statistics and Agreement}

The mean and standard deviation of Likert-type responses were calculated for each item on both caregiver and adolescent reports of the SAS-A. Comparison between caregiver and adolescent responses on all items was conducted using paired-samples $t$-tests with the Holm-Bonferroni correction (Aickin \& Gensler, 1996; Holm, 1979). Weighted Cohen's kappa and polychoric correlations were used to examine caregiver-adolescent agreement for each item. Weighted Cohen's kappa is a measure of consistency between raters for ordinal data, in which mismatched judgments that are further apart (e.g., not at all vs. all of the time) are penalized more heavily than mismatched judgments that are closer together (e.g., most of the time vs. all of the time). The polychoric correlation describes the relation between the two normally distributed latent variables that are assumed to underlie the observed ordered categorical response distributions for each item.

\section{Factor Structure}

A series of confirmatory factor analyses (CFAs) were employed to evaluate a one-factor, two-factor, and, the literature-standard, three-factor structure of caregiver and adolescent reports on the SAS-A. This method, however, does not enable items to cross-load on multiple factors unless they are specified a priori (theoretically driven) or identified through modification indices (data-driven). Without theoretical support for cross-loadings, a data-driven approach limits the generalization of the findings. Thus, two-factor and three-factor exploratory factor analysis (EFA) models with oblimin rotation were also considered; geomin rotation was also tried and revealed identical factor interpretations. For all models, parameters were estimated using mean- and variance-adjusted weighted least squares (WLSMV as implemented in Mplus) to account for the categorical nature of the item responses. Based on previous research examining the SAS-A, factors were allowed to covary in the CFAs. Model fit was evaluated using multiple goodness-of-fit statistics, including the root mean square error of approximation (RMSEA), the comparative fit index (CFI), and the Tucker-Lewis Index (TLI). While general guidelines exist for "poor," "acceptable," and "good" levels of model fit 
(e.g., Browne \& Cudeck, 1993; Hu \& Bentler, 1999), these guidelines were developed under normal theory maximum likelihood with continuous indicators, not categorical indicators. Thus, in the present study, the authors considered the entire collection of fit statistics in evaluating model fit, with the general goal of obtaining RMSEA values less than 0.08 (Browne \& Cudeck, 1993) and CFI and TLI values greater than 0.95 (Hu \& Bentler, 1999). All factor analyses were conducted using Mplus version 7.4 (Muthén \& Muthén, 1998-2012).

\section{Measurement Invariance}

In order to test measurement invariance between the caregiver and adolescent forms, and thus explore the possible contribution of measurement invariance to item-level agreement and differences, a repeated measures design was utilized such that caregiver and adolescent reports were nested within the unit of analysis: the adolescent. Therefore, 36 items (18 self-report, 18 caregiver report) corresponded to each adolescent; this inherently implies that residual variances for each item should be correlated between reporters. A path diagram showing the correlated residual structure of the measurement invariance models is shown in Figure 1. Multiple models were systematically tested to assess (1) configural invariance (Model 1): factor structure is equivalent across groups, with similar patterns of factor loadings and factor intercorrelations; (2) metric/weak invariance (Model 2): factor loadings are constrained to be equal across reporters; (3) threshold/strong invariance (Model 3): thresholds are constrained to be equal across reporters; and (4) residual variance/strict invariance (Model 4): residual variances are constrained to be equal across reporters. Table 2 displays further details of the measurement invariance models that were tested. Successive models were compared using a corrected chi-square difference test for nested models (Liu et al., 2017); lack of a significant difference in model chi-square values supports the more highly constrained and, thus, more parsimonious, model.

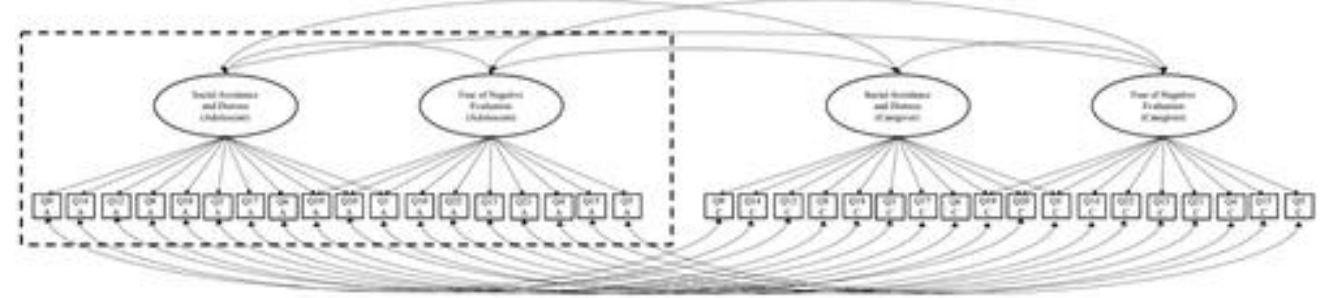

Figure 1. Overall diagram: Model setup for measurement invariance testing across multiple reporters. Note. Diagram enclosed in the dashed box indicates the factor structure of the final model within a particular sample (adolescent or caregiver). 
Table 2. Measurement Invariance Models.

\begin{tabular}{|c|c|c|c|c|c|c|c|c|c|c|}
\hline & Adolescent & & & & & Caregiver & & & & \\
\hline & $\begin{array}{l}\text { Factor } \\
\text { loadings }\end{array}$ & Thresholds & $\begin{array}{l}\text { Residual } \\
\text { variances }\end{array}$ & $\begin{array}{l}\text { Factor } \\
\text { means }\end{array}$ & $\begin{array}{l}\text { Factor } \\
\text { variances }\end{array}$ & $\begin{array}{l}\text { Factor } \\
\text { loadings }\end{array}$ & Thresholds & $\begin{array}{l}\text { Residual } \\
\text { variances }\end{array}$ & $\begin{array}{l}\text { Factor } \\
\text { means }\end{array}$ & $\begin{array}{l}\text { Factor } \\
\text { variances }\end{array}$ \\
\hline Model 1 & Free & Free & Fixed 1 & Fixed 0 & Fixed 1 & Free & Free & Fixed 1 & Fixed 0 & Fixed 1 \\
\hline Model 2 & Constrained & Free & Fixed 1 & Fixed 0 & Fixed 1 & Constrained & Free & Fixed 1 & Fixed 0 & Free \\
\hline Model 3 & Constrained & Constrained & Fixed 1 & Fixed 0 & Fixed 1 & Constrained & Constrained & Fixed 1 & Free & Free \\
\hline Model 4A & Constrained & Constrained & Fixed 1 & Fixed 0 & Fixed 1 & Constrained & Constrained & Free & Free & Free \\
\hline Model 4B & Constrained & Constrained & Fixed 1 & Fixed 0 & Fixed 1 & Constrained & Constrained & Fixed 1 & Free & Free \\
\hline
\end{tabular}




\section{Validity}

Convergent validity was evaluated by correlating the SAS-A factor scores on another measure of social anxiety (SIAS total score). Discriminant validity of the SAS-A was evaluated by correlating the factor scores with measures of depressive symptoms (SMFQ total score) and autism symptoms (SRS-2 total score). The selection of these constructs was theoretically driven. Significant differences between correlations were estimated using Fischer's $r$ to $z$ transformation, calculating asymptotic covariance of the estimates, and conducting a $z$ test using an online program (Lee \& Preacher, 2013). Strengths of associations were classified as strong (from 0.5 to 1 ), moderate (from 0.3 to 0.49 ), or weak (from 0 to 0.29).

\section{Results}

\section{Item-Level Descriptive Statistics and Agreement}

Table 3 displays item-level means, standard deviations, and agreement statistics for caregiver and adolescent reports on the SAS-A. Adolescent responses range from a mean of 2.09 to 3.32; caregiver responses range from a mean of 2.35 to 3.57. The item with the highest endorsement by adolescents is Q5 ("I only talk to people I know really well") and by caregivers is Q22 ("It's hard for my child to ask others to do things with them"). The item with the lowest endorsement by adolescents is Q21 ("I feel shy even with peers I know very well") and by caregivers is Q18 ("If my child gets into an argument, they worry that the other person will not like them"). A consistent pattern emerges with caregivers endorsing higher levels of social anxiety than adolescents on all items except two: Q5, which was the highest endorsed item by adolescents and Q18, which was the lowest endorsed item by caregivers. More than half of these differences were statistically significant (Table 3). 
Table 3. Item-Level Descriptive Statistics and Agreement.

\begin{tabular}{|c|c|c|c|c|c|c|}
\hline & Adolescent & & Caregiver & & $\begin{array}{l}\text { Adolescent-caregiver } \\
\text { agreement }\end{array}$ & \\
\hline Item number and key concept & $N$ & $M(S D)$ & $N$ & $M(S D)$ & Weighted kappa & $\begin{array}{l}\text { Polychoric } \\
\text { correlation }\end{array}$ \\
\hline Q1: Performance in front of others ${ }^{a}$ & 196 & $2.71(1.26)$ & 167 & $3.53(1.14)$ & 0.13 & 0.18 \\
\hline Q3: Being teased ${ }^{a}$ & 197 & $2.59(1.36)$ & 166 & $3.22(1.17)$ & 0.17 & 0.23 \\
\hline Q4: Shy around unfamiliar people ${ }^{a}$ & 197 & $3.06(1.41)$ & 167 & $3.40(1.21)$ & 0.23 & 0.26 \\
\hline Q5: Only talk to familiar people & 196 & $3.32(1.35)$ & 167 & $3.11(1.28)$ & 0.09 & 0.10 \\
\hline Q6: Peer gossip & 196 & $2.45(1.36)$ & 166 & $2.54(1.31)$ & 0.23 & 0.25 \\
\hline Q8: Others' evaluations & 196 & $2.74(1.36)$ & 166 & $2.91(1.25)$ & 0.23 & 0.26 \\
\hline Q9: Others dislike ${ }^{a}$ & 197 & $2.56(1.39)$ & 167 & $2.93(1.29)$ & 0.29 & 0.31 \\
\hline Q10: Talk to unfamiliar peers ${ }^{a}$ & 197 & $2.75(1.33)$ & 167 & $3.45(1.20)$ & 0.21 & 0.27 \\
\hline Q12: What others say about me & 197 & $2.56(1.29)$ & 167 & $2.73(1.19)$ & 0.33 & 0.34 \\
\hline Q13: Meet new people ${ }^{a}$ & 196 & $2.85(1.28)$ & 167 & $3.36(1.23)$ & 0.21 & 0.25 \\
\hline Q14: Others don't like me $\mathrm{a}^{\mathrm{a}}$ & 197 & $2.52(1.36)$ & 166 & $2.83(1.23)$ & 0.35 & 0.39 \\
\hline Q15: Quiet with a group & 197 & $2.98(1.24)$ & 167 & $3.26(1.18)$ & 0.25 & 0.28 \\
\hline Q17: Am being teased ${ }^{\mathrm{a}}$ & 197 & $2.42(1.38)$ & 167 & 2.84 (1.19) & 0.27 & 0.32 \\
\hline Q18: Rejection due to argument & 197 & $2.45(1.34)$ & 166 & $2.35(1.13)$ & 0.16 & 0.18 \\
\hline Q19: Rejection of social invitation & 197 & $2.29(1.27)$ & 167 & $2.51(1.33)$ & 0.16 & 0.20 \\
\hline Q20: Being around certain people ${ }^{a}$ & 195 & $2.81(1.33)$ & 167 & $3.26(1.04)$ & 0.13 & 0.14 \\
\hline Q21: Shy with familiar peers ${ }^{a}$ & 197 & $2.09(1.22)$ & 167 & $2.42(1.18)$ & 0.20 & 0.24 \\
\hline Q22: Social invitation ${ }^{\mathrm{a}}$ & 196 & $2.66(1.37)$ & 167 & $3.57(1.26)$ & 0.16 & 0.23 \\
\hline
\end{tabular}

aPaired-samples $t$ tests indicate significant difference between adolescent and caregiver item mean using alpha criterion of 0.05 and HolmBonferroni correction. 
Across all items, agreement between caregivers and adolescents is poor based on both Cohen's weighted kappas (0.09 to 0.35 ) and polychoric correlations ( 0.10 to 0.39 ). The item with the highest agreement (kappa $=0.35$, polychoric correlation $=0.39$ ) is Q14 (“I/My child worry(ies) that others don't like me/them"). The item with the lowest agreement (kappa $=0.09$, polychoric correlation $=0.10$ ) is Q5 ("I/My child only talk(s) to people I/they know really well").

\section{Factor Structure}

Table 4 shows the goodness-of-fit statistics for caregiver and adolescent CFA and EFA models. The onefactor CFA demonstrates poor fit for both caregiver and adolescent reports, with model fit statistics substantially below optimal values (Adolescent: $\mathrm{CFI}=0.89, \mathrm{TLI}=0.88, \mathrm{RMSEA}=0.14$; Caregiver: $\mathrm{CFI}=$ $0.85, \mathrm{TLI}=0.83, \mathrm{RMSEA}=0.21$ ). The two-factor and three-factor (literature standard) CFAs show improved fit over the one-factor model; these CFA models, however, exhibit only mediocre to unacceptable fit (Table 4). The SAD factors (SAD-N and SAD-G) in the three-factor CFA are highly positively correlated in both samples (Adolescent: $r=0.92$, Caregiver: $r=0.82$ ), suggesting that a single SAD factor sufficiently underlies responses to all 10 items (Finch, 2006). Thus, for subsequent CFA models, only the two-factor model was considered. 
Table 4. Factor Analysis Model Comparisons.

\begin{tabular}{|c|c|c|c|c|c|c|c|c|}
\hline & Adolescent & & & & Caregiver & & & \\
\hline & $\chi^{2}(d f)$ & $\mathrm{CFI}$ & TLI & RMSEA [90\% Cl] & $\chi^{2}(d f)$ & $\mathrm{CFI}$ & TLI & RMSEA $[90 \% \mathrm{Cl}]$ \\
\hline One-factor CFA & $626.03(135)$ & 0.89 & 0.88 & $0.14[0.13,0.15]$ & $1107.57(135)$ & 0.85 & 0.83 & $0.21[0.20,0.22]$ \\
\hline Two-factor CFA & $364.12(134)$ & 0.95 & 0.94 & $0.09[0.08,0.11]$ & $455.12(134)$ & 0.95 & 0.94 & $0.12[0.11,0.13]$ \\
\hline Three-factor CFA (literature standard) & $363.72(132)$ & 0.95 & 0.94 & $0.09[0.08,0.11]$ & $446.66(132)$ & 0.95 & 0.94 & $0.12[0.11,0.13]$ \\
\hline Two-factor EFA & $260.5(118)$ & 0.97 & 0.96 & $0.08[0.07,0.09]$ & $306.40(118)$ & 0.97 & 0.97 & $0.10[0.08,0.11]$ \\
\hline Three-factor EFA & $220.82(102)$ & 0.97 & 0.96 & $0.08[0.06,0.09]$ & $217.15(102)$ & 0.98 & 0.97 & $0.08[0.07,0.10]$ \\
\hline Two-factor CFA with Q19 cross-loading & $341.89(133)$ & 0.953 & 0.95 & $0.09[0.08,0.10]$ & $397.73(133)$ & 0.96 & 0.95 & $0.11[0.10,0.12]$ \\
\hline Two-factor CFA with Q19 and Q20 cross-loadings & $320.60(132)$ & 0.96 & 0.95 & $0.09[0.07,0.10]$ & $361.37(132)$ & 0.97 & 0.96 & $0.10[0.09,0.12]$ \\
\hline Two-factor CFA with Q19, Q20, and Q1 cross-loadings & 289.74(131) & 0.96 & 0.96 & $0.08[0.07,0.09]$ & 320.93(131) & 0.97 & 0.97 & $0.09[0.08,0.11]$ \\
\hline
\end{tabular}

Note. $\mathrm{df}=$ degrees of freedom; $\mathrm{CFI}=$ comparative fit index; TLI = Tucker-Lewis index; RMSEA = root mean square error of approximation; EFA = exploratory factor analysis; $\mathrm{Cl}=$ confidence interval. Final model for each sample is shown in bold. 
Due to the estimation of all possible cross-loadings, the fit indices of the two-factor and three-factor EFAs show improvement over the CFA models (Table 4), which do not allow any cross-loadings. While the EFA models exhibit superior fit, they also lack parsimony due to the large number of estimated cross-loadings. For this reason, the EFA models were used to identify items that had substantial crossloadings (standardized factor loading greater than 0.30) and to confirm that the SAD items are best represented by a single factor. Indeed, the EFAs support a two-factor model. To balance model parsimony with model fit, cross-loadings were then estimated within a two-factor CFA framework, in which all other cross-loadings were fixed to zero.

Examination of EFA factor loadings suggest three items with substantial cross-loadings. The crossloadings for these items were then estimated sequentially as part of the two-factor CFA, with model fit examined at each step to determine whether additional cross-loadings were needed. The best-fitting model allows estimation of all three cross-loadings: Q19 (“I’m/My child (is) afraid to invite others to do things with me because they might say no"), Q20 ("I/My child feel(s) nervous when I'm around certain people"), and Q1 ("I/My child worry(ies) about doing something new in front of others"; Table 4). These items have the largest cross-loadings for both the adolescent and caregiver models. Figure 1 includes a path diagram of this final model (fit indices for adolescents: $\mathrm{RMSEA}=0.07, \mathrm{CFI}=0.97, \mathrm{TLI}=$ 0.97; fit indices for caregivers: $\mathrm{RMSEA}=0.09, \mathrm{CFI}=0.97, \mathrm{TLI}=0.97)$. Within the adolescent sample, coefficient alpha for the SAD and FNE factors is 0.86 and 0.91 , respectively; within the caregiver sample, coefficient alpha for the SAD and FNE factors is 0.89 and 0.92 , respectively.

Factor loadings and thresholds for the final model can be found in Table 5. The magnitudes of the factor loadings for the FNE subscale demonstrate a relatively consistent pattern for both adolescents and caregivers, with Spearman's correlation $\left(r_{s}=.91, p<.001\right)$ indicating a similar rank-order of factor loadings across reporters. The order of items based on factor loadings is less consistent across reporters for the SAD items $\left(r_{s}=.70, p<.05\right)$. Q9 ("I'm/My child (is) afraid that others will not like me") is the highest loading item on FNE for both adolescent and caregiver report. Q10 ("I/My child get(s) nervous when I talk to peers I don't know very well") has the highest factor loading on SAD for both adolescent and caregiver report. FNE and SAD are positively correlated for both reporters, though to a noticeably lesser degree for caregivers than adolescents (Adolescent: $r=.63$, Caregiver: $r=.35$ ). 
Table 5. CFA Parameter Estimates From the Final Model.

\begin{tabular}{|c|c|c|c|c|}
\hline & & Adolescent & & Caregiver \\
\hline Item & $\begin{array}{l}\text { Standardized } \\
\text { factor loading (SE) }\end{array}$ & Thresholds & $\begin{array}{l}\text { Standardized factor loading } \\
\text { (SE) }\end{array}$ & Thresholds \\
\hline \multicolumn{5}{|l|}{ Fear of negative evaluation (FNE) } \\
\hline Q9: Others dislike & $0.93(0.01)$ & $-0.54,0.12,0.63,1.09$ & $0.94(0.01)$ & $-0.99,-0.20,0.30,1.14$ \\
\hline Q14: Others don't like me & $0.87(0.02)$ & $-0.53,0.12,0.73,1.12$ & $0.90(0.02)$ & $-0.94,-0.23,0.45,1.34$ \\
\hline Q12: What others say about me & $0.86(0.02)$ & $-0.63,0.03,0.76,1.22$ & $0.90(0.02)$ & $-0.89,-0.17,0.61,1.42$ \\
\hline Q8: Others' evaluations & $0.84(0.02)$ & $-0.74,-0.11,0.63,0.98$ & $0.93(0.01)$ & $-1.01,-0.27,0.42,1.17$ \\
\hline Q18: rejection due to argument & $0.79(0.03)$ & $-0.42,0.14,0.77,1.16$ & $0.67(0.04)$ & $-0.59,0.18,1.01,1.73$ \\
\hline Q3: Being teased & $0.69(0.04)$ & $-0.57,0.03,0.63,1.14$ & $0.80(0.03)$ & $-1.42,-0.59,0.20,1.01$ \\
\hline Q17: Am being teased & $0.67(0.04)$ & $-0.38,0.20,0.76,1.14$ & $0.78(0.03)$ & $-1.01,-0.28,0.58,1.27$ \\
\hline Q6: Peer gossip & $0.64(0.05)$ & $-0.44,0.14,0.76,1.13$ & $0.75(0.04)$ & $-0.54,0.01,0.68,1.30$ \\
\hline Q19: Rejection of social invitation & $0.45(0.07)$ & $-0.38,0.30,0.96,1.33$ & $0.40(0.06)$ & $-0.47,0.08,0.57,1.38$ \\
\hline Q20: Being around certain people & $0.34(0.05)$ & $-0.75,-0.28,0.62,1.02$ & $0.29(0.06)$ & $-1.67,-0.73,0.19,1.21$ \\
\hline Q1: Performance in front of others & $0.33(0.06)$ & $-0.81,-0.15,0.72,1.16$ & $0.29(0.07)$ & $-1.51,-0.96,-0.10,0.75$ \\
\hline \multicolumn{5}{|l|}{ Social avoidance and distress (SAD) } \\
\hline Q10: Talk to unfamiliar peers & $0.82(0.03)$ & $-0.74,-0.12,0.53,1.14$ & $0.91(0.02)$ & $-1.46,-0.77,-0.04,0.75$ \\
\hline Q22: Social invitation & $0.79(0.04)$ & $-0.63,-0.05,0.66,1.04$ & $0.56(0.06)$ & $-1.24,-0.87,-0.27,0.63$ \\
\hline Q13: Meet new people & $0.76(0.04)$ & $-0.92,-0.28,0.63,1.02$ & $0.91(0.02)$ & $-1.34,-0.67,0.01,0.83$ \\
\hline Q21: Shy with familiar peers & $0.69(0.05)$ & $-0.19,0.51,1.07,1.51$ & $0.76(0.04)$ & $-0.61,0.13,0.92,1.56$ \\
\hline Q4: Shy around unfamiliar people & $0.63(0.05)$ & $-0.89,-0.33,0.26,0.78$ & $0.85(0.03)$ & $-1.56,-0.60,-0.05,0.79$ \\
\hline Q15: Quiet with a group & $0.52(0.05)$ & $-1.07,-0.43,0.50,1.03$ & $0.64(0.05)$ & $-1.24,-0.75,0.16,1.01$ \\
\hline Q5: Only talk to familiar people & $0.49(0.06)$ & $-1.14,-0.60,0.11,0.61$ & $0.71(0.04)$ & $-1.01,-0.42,0.07,1.15$ \\
\hline Q20: Being around certain people & $0.49(0.05)$ & $-0.75,-0.28,0.62,1.02$ & $0.58(0.05)$ & $-1.67,-0.73,0.19,1.21$ \\
\hline Q1: Performance in front of others & $0.46(0.06)$ & $-0.81,-0.15,0.73,1.16$ & $0.53(0.05)$ & $-1.51,-0.96,-0.10,0.75$ \\
\hline Q19: Rejection of social invitation & $0.30(0.07)$ & $-0.38,0.30,0.96,1.33$ & $0.33(0.06)$ & $-0.47,0.08,0.57,1.38$ \\
\hline FNE with SAD, correlation (SE) & & $0.63(0.04)$ & & $0.35(0.07)$ \\
\hline
\end{tabular}

Note. SE = standard error. Refer to La Greca and Lopez (1998) for exact wording of items. 


\section{Measurement Invariance}

Results of the measurement invariance analysis are presented in Table 6. Configural invariance indicates that the same factor structure is present for both adolescents and caregivers. While there is no formal statistical test for this type of invariance, a similar pattern of factor loadings in both samples suggests that configural invariance holds between reporters. After constraining factor loadings to be invariant between adolescent and caregiver reports (i.e., testing metric/weak invariance), a significant corrected chi-square difference test indicates a significant decline in model fit; thus, metric/weak invariance does not hold (Table 6). Partial metric invariance (not shown in Table 6) was subsequently tested by systematically constraining one loading per factor at a time to be equal between the two reporters, treating all other items as anchors. No evidence for partial invariance was found; that is, any time a single-factor loading was constrained to be equal between the two groups, while all others were freely estimated, model fit significantly worsened. For purposes of completeness, tests of threshold/strong invariance and residual variance/strict invariance are shown in the online supplemental materials; however, because weak invariance does not hold, results of the subsequent invariance tests necessarily indicated a significantly worse fitting model as more parameter constraints were imposed. While the item response data from both the adolescent and caregiver forms exhibit a similar factor structure, there is inequality in most of the item parameter estimates.

Table 6. Measurement Invariance Model Comparisons.

\begin{tabular}{|l|l|l|l|l|l|l|l|}
\hline Invariance model & $\begin{array}{l}\text { Constrained } \\
\text { to be } \\
\text { invariant }\end{array}$ & $X^{2}(d f)$ & $\begin{array}{l}\text { Corrected } \\
\Delta X^{2} \text { test } \\
(\Delta d f)\end{array}$ & $\begin{array}{l}p \text { Value from } \\
\text { corrected } \\
X^{2} \text { difference } \\
\text { test }\end{array}$ & CFI & TLI & RMSEA [95\% Cl) \\
\hline $\begin{array}{l}\text { Model 1: } \\
\begin{array}{l}\text { Configural } \\
\text { invariance }\end{array}\end{array}$ & None & $762.81(562)$ & -- & -- & 0.98 & 0.98 & $0.04[0.034,0.050]$ \\
\hline $\begin{array}{l}\text { Model 2: } \\
\text { Metric/weak } \\
\text { invariance }\end{array}$ & $\mathrm{F}$ & $971.48(583)$ & $143.45(21)$ & $<.001$ & 0.96 & 0.95 & $0.06[0.05,0.06]$ \\
\hline
\end{tabular}

Note: $\mathrm{df}=$ degrees of freedom; $\mathrm{CFI}=$ comparative fit index; $\mathrm{TLI}=$ Tucker-Lewis index; RMSEA=root mean square error of approximation; F=factor loadings.

\section{Validity}

Validity analyses reveal modest evidence for convergent and discriminant validity of the SAS-A (Table 7).

Table 7. Validity With SAS-A Factor Scores.

\begin{tabular}{|l|l|l|l|l|l|l|}
\hline & Adolescent & & & Caregiver & & \\
\hline & $\mathrm{N}$ & FNE & SAD & N & FNE & SAD \\
\hline SIAS total score & 197 & $0.60^{* *}$ & $0.76^{* *}$ & 165 & $0.26^{* *}$ & $0.19^{*}$ \\
\hline SMFQ total adolescent report & 121 & $0.43^{* *}$ & $0.35^{* *}$ & 113 & $0.29^{* *}$ & 0.03 \\
\hline SMFQ total caregiver report & 121 & $0.41^{* *}$ & $0.23^{*}$ & 114 & $0.53^{* *}$ & 0.17 \\
\hline SRS Total score & 194 & 0.06 & -0.06 & 166 & $0.22^{* *}$ & $0.30^{* *}$ \\
\hline
\end{tabular}

Note: SAS-A=Social Anxiety Scale for Adolescents; FNE=fear of negative evaluation; SAD-social avoidance and distress; SMFQ=Short Mood and Feelings Questionnaire; SIAS=Social Interaction Anxiety Scale; SRS=Social Responsiveness Scale. 
${ }^{*} p<.05 .{ }^{*} \mathrm{p}<.01$.

\section{SAS-A Adolescent Form}

Significant strong positive associations emerge between adolescent SAS-A factor scores and the total score on the SIAS, a self-report measure of social anxiety $\left(r_{\mathrm{FNE}}=.60\right.$ and $\left.r_{\mathrm{SAD}}=.76\right)$, providing evidence for convergent validity. Scores on the SMFQ (both adolescent and caregiver report) are moderately positively correlated with the adolescent-reported FNE and SAD factors (Adolescent SMFQ: $r_{\mathrm{FNE}}=.43$ and $r_{\mathrm{SAD}}=.35$, Caregiver SMFQ: $r_{\mathrm{FNE}}=.41$ and $r_{\mathrm{SAD}}=.23$ ). The association between the adolescent SAS-A factor scores and the SIAS are significantly stronger than the associations between the adolescent SASA factor scores and both adolescent and caregiver report on the SMFQ (Adolescent SMFQ: $Z_{\mathrm{FNE}}=$ 2.03, $p=.04, z_{\mathrm{SAD}}=5.48, p<.01$; Caregiver SMFQ: $\left.z_{\mathrm{FNE}}=2.17, p=.03 ; z_{\mathrm{SAD}}=6.57, p<.01\right)$, thus providing some evidence of discriminant validity. There are no significant associations, however, between the SRS and either of the adolescent SAS-A factor scores.

\section{SAS-A Caregiver Form}

There are weak positive correlations between the caregiver SAS-A factor scores and SIAS $\left(r_{\mathrm{FNE}}=.26\right.$ and $\left.r_{S A D}=.19\right)$. Only the caregiver FNE factor scores are significantly associated with the SMFQ, on both caregiver $\left(r_{\mathrm{FNE}}=.53\right)$ and adolescent $\left(r_{\mathrm{FNE}}=.29\right) \mathrm{SMFQ}$ forms. The correlation between FNE and SMFQ caregiver is significantly stronger than the correlation between FNE and SIAS ( $\left.z_{\mathrm{FNE}}=2.82, p=.01\right)$. Finally, there are weak positive associations between caregiver-reported autism symptoms (SRS) and caregiver FNE and SAD factor scores $\left(r_{\mathrm{FNE}}=.22\right.$ and $\left.r_{\mathrm{SAD}}=.30\right)$; these associations are not significantly different from the correlations between the caregiver SAS-A factor scores and the SIAS.

\section{Discussion}

The present study examined self- and caregiver-reported responses on the SAS-A among a sample of adolescents with ASD. More specifically, caregiver-adolescent item-level agreement, factor structure, measurement invariance, and validity of the SAS-A were evaluated. Overall, the results suggest that a two-factor structure holds for both the adolescent and caregiver forms, and that this measure demonstrates reasonable psychometric properties in an ASD sample, as indicated by coefficient alpha and model fit statistics. Due to a lack of measurement invariance beyond the configural level, however, factor score and mean-level comparisons between adolescent and caregiver forms is problematic. Thus, researchers should exercise caution in drawing inferences about factor score differences between adolescents and their caregivers, as there is evidence that the measure may not perform similarly (i.e., different factor loadings and thresholds) for both reporters.

Findings also revealed poor item-level agreement between caregivers and adolescents on the SAS-A. This is in line with previous research on anxiety in ASD; other studies have similarly identified poor item-level caregiver-child agreement on measures of anxiety in ASD samples (e.g., Screen for Child Anxiety Related Emotional Disorders in Children; Blakeley-Smith et al., 2012). At the item level, caregivers in the current sample endorsed significantly higher levels (i.e., greater frequency) of social anxiety symptoms compared with adolescents on many items. The observed poor agreement and discrepancies could be due to true differences in parent and adolescent perception of anxious symptoms, but importantly, could also be due to differences in the psychometric properties of the caregiver and adolescent forms. That is, a critical follow-up analysis was testing measurement 
invariance across reporters, which revealed lack of evidence for even partial metric invariance. Therefore, both item-level agreement and discrepancies across caregivers and adolescents certainly could be, in part, attributable to differences in measurement properties.

Related to real differences in perceptions of anxious symptoms, these results may also suggest that caregivers perceive their child's anxious symptoms as more severe or more frequently occurring than the adolescents themselves, at least at the item level. This pattern might be due to a heightened sensitivity to perceive secondary challenges in their child. Given the identified association between caregiver-reported social anxiety and autism symptoms, an inflated or conflated perception of anxiety is possible, especially for those caregivers who perceive greater levels of autism severity. Additionally, considering the potential difficulty with introspection in ASD (Williams, 2010), it might also be that for some adolescents with ASD, there are hinderances to recognizing an internal state of anxiety and, therefore, lower levels were reported. Although to the authors' knowledge, no studies have examined mean item-level discrepancies between reporters on measures of anxiety in ASD, these conclusions are in parallel with other work that has identified greater levels of caregiver-reported anxiety compared with child report at the scale and subscale levels (e.g., Lopata et al., 2010) and are in contrast to those studies that suggest no difference in perception of anxiety (e.g., Burrows et al., 2018) and those that report heightened symptom perception in children compared with parents (e.g., Ooi et al., 2016). Moreover, as will be discussed in greater detail, however, conclusions should be interpreted cautiously for tools that lack evidence for measurement invariance.

Evidence from the present analyses suggests that the standard three-factor structure that has been found within typically developing samples (La Greca \& Lopez, 1998) did not hold in the present sample of adolescents with ASD. Instead, a two-factor structure (FNE and SAD) was identified. To some extent, caregivers and youth with ASD differentiated between apprehension related to potentially negative evaluative situations (FNE) and avoidance of social interaction coupled with unpleasant emotions in social situations (SAD). The correlations between these two factors were weak (for caregivers) or moderate (for adolescents), suggesting that they assess distinct dimensions of social anxiety. It is important to note that, given the potential for reduced social reward in ASD (Chevallier, Kohls, Troiani, Brodkin, \& Schultz, 2012), social disinterest may affect adolescents' responses on some of the SAD items and, thus, the SAD factor may be capturing a different construct here than in a non-ASD sample. More specifically, while some youth with ASD may desire social engagement, yet avoid social situations due to worry and fear, other youth with ASD may, in fact, avoid social situations due a lack of social anhedonia. The present study, however, was unable to disentangle avoidance behaviors due to social anhedonia from those due to worry or fear.

Previous research on the SAS in typically developing samples has identified two separate, yet related ( $r=.55$, La Greca \& Lopez, 1998; $r=.59$, Inderbitzen-Nolan \& Walters, 2000), underlying SAD factors (SAD-N and SAD-G; Inderbitzen-Nolan \& Walters, 2000; La Greca \& Lopez, 1998). In contrast, the current results suggest that a single SAD factor sufficiently underlies responses to all 10 SAD items for adolescents with ASD. Perhaps the heightened social difficulties of ASD minimize the distinction between avoidance and distress related to general social situations compared with novel social situations from the perspective of both caregivers and adolescents; any social situation, novel or otherwise, might elicit avoidance and distress. Therefore, commensurate with previous research 
suggesting the unique presentation of anxiety in ASD (e.g., Kerns et al., 2014), the presentation of social anxiety in ASD may also be distinct for this clinical group. Thus, these findings also have implications for previous research that has interpreted the SAS at the subscale level and, more specifically, differentiated between SAD-N and SAD-G, in samples of youth with ASD.

Additionally, three items (Q1, Q19, and Q20) had sizable loadings on both FNE and SAD factors. In previous studies of typically developing youth, these items were found to load only onto a SAD-related factor. Q19 ("I'm afraid to invite others to do things with me because they might say no") references distress and avoidance of a particular social situation (i.e., arranging a get together) in addition to an implied evaluative and rejection-related apprehension ("because they might say no"). Therefore, in an ASD sample, responses to this item are likely driven by a combination of both FNE and SAD. Items Q1 and Q20 involve experiencing unpleasant emotions (nervousness and worry) around certain people or in front of others. Considering the high occurrence of victimization (Van Roekel, Scholte, \& Didden, 2010) and social isolation (Hall-Lande, Eisenberg, Christenson, \& Neumark-Sztainer, 2007) in this population, youth with ASD may experience fear-related emotions in these particular situations, in part, due to apprehension related to past actual or perceived rejection (a type of evaluation). Thus, these separate constructs may become conflated.

The same final-factor structure was identified for both caregivers and adolescents, providing evidence for configural invariance. This implies that the same underlying factors are present for caregivers and adolescents with ASD. Further measurement invariance testing, however, suggests that higher levels of measurement invariance did not hold between reporters. That is, the way in which these factors influenced responses to items (i.e., factor loadings) and the amount of social anxiety required to endorse the items (i.e., thresholds) appeared to differ for caregivers and adolescents. It might be that dissimilarities in how the instrument functions for caregivers compared with adolescents plays a role in differences (or lack of differences) on scale and subscale scores, rather than true distinctions in the underlying construct. Therefore, lack of measurement invariance precludes comparison between caregiver and adolescent report using factor scores (or mean-level scores) on the SAS-A, and may also influence item-level differences as well. These findings have implications for previous and future research using the SAS-A among ASD samples, particularly if the intent is to use caregiver responses as a proxy for adolescent responses.

While caregiver-adolescent agreement and measurement invariance were suboptimal for the SAS-A in this sample, results revealed an expected pattern of correlations between the SAS-A factor scores and other measures often used in autism research, especially for the adolescent report. The findings provide some evidence for convergent validity with the SIAS, a self-report measure of social anxiety; less compelling evidence for convergent validity of the caregiver version of the SAS-A was uncovered, likely due to the confound of reporter. Additionally, there was modest evidence of discriminant validity with measures of depressive symptoms (SMFQ) and autism symptoms (SRS). That is, there were positive correlations between factor scores on the SAS-A and depressive symptoms. This is commensurate with the robust association between anxiety and depression both in typical development (Brady \& Kendall, 1992; Cummings, Caporino, \& Kendall, 2014) and ASD samples (Mayes, Calhoun, Murray, \& Zahid, 2011; Sterling, Dawson, Estes, \& Greenson, 2008). For adolescent report, the magnitude of the depression correlations was significantly weaker than those between the SAS-A 
and the SIAS, supporting discriminant validity. For caregiver report, however, the depression correlations were either no different or stronger than the SAS-A and SIAS associations, which provides little support for divergent validity; this pattern is likely confounded by differences in reporter, given that the SIAS is self-report. Furthermore, it is documented that the presence of anxiety is linked with greater reports of social difficulties for those with ASD (e.g., White \& Roberson-Nay, 2009), and, in particular, SRS scores (Factor et al., 2017; McVey et al., 2018). While caregiver report on the SAS-A was positively correlated with the SRS, the association was not significantly different from the correlation between the SAS-A and the SIAS - given that SRS is parent report and SIAS is self-report, these findings are not unexpected. Additionally, no association emerged between adolescent report on the SAS-A and the SRS. The findings that do not support validity (SAS-A caregiver with SIAS; SAS-A adolescent with SRS) are likely more attributable to reporter effects (within or between reporter) than to properties of the SAS-A itself. Taken together, this pattern of correlations suggests that, at least to some extent, the SAS-A is able to measure social anxiety in an ASD sample. Because the psychometric properties of the criterion measures were not evaluated, however, interpretation of construct validity in ASD is more limited.

Taken together, findings from the present study are meaningful for autism research, as they begin to fill a critical gap in current knowledge of measurement of social anxiety within this population. This study highlights the potential limitations of using measures developed for use with non-ASD samples among people with ASD. As such, it is critical that researchers carefully choose measures that have strong psychometric properties in samples with ASD or, if measures are unavailable, emphasize the limitations of using measures with unknown psychometric properties within particular samples. Given these implications, there is a pressing need for additional research on the measurement of cooccurring anxiety symptoms in ASD, and, perhaps, the development of new measures that are designed specifically to tap into the unique presentation of anxiety for people with ASD (e.g., Rodgers et al., 2016).

This study has implications for clinical practice as well. In particular, proper identification of social anxiety symptoms that extend above and beyond core autism symptoms is of utmost importance. Notably, findings from the current study suggest that assessing social anxiety in an adolescent with ASD may differ from assessing social anxiety in an adolescent without ASD. Moreover, the results of this study also highlight the differing perspectives that caregivers and adolescents have on youths' symptoms of social anxiety. Although this study does not clarify whose report is more reliable or valid for any particular use (e.g., diagnosing social anxiety), it emphasizes the importance of gathering information from multiple informants when making diagnostic decisions for youth with ASD. Finally, the results of the current analyses suggest that, while the SAS-A is a useful tool for adolescents with ASD, for the sake of scoring simplicity, researchers may decide to exclude cross-loading items or items that less effectively measure each construct (i.e., less discriminating items) in future work; in this case Q1, Q19, and Q20 may be considered candidates for exclusion, given that they cross-load onto both factors and are the least discriminating.

The present study was not without its limitations, and many of these provide potential directions for future research. The sample was limited in terms of size and diversity. Therefore, these findings may not generalize to the larger autism population. Furthermore, given the lack of a typically developing 
comparison sample, measurement invariance between the ASD sample and a sample without ASD was not formally tested. Because the factor structure found in the present study differed from that found in non-ASD samples, it is likely that measurement invariance would not hold; future research should seek to formally evaluate measurement invariance between an ASD and a typically developing sample on the SAS-A. Additionally, validity analyses were limited to self-report of social anxiety and caregiver report of autism symptoms due to the post hoc nature of this study. For future psychometric analyses of the SAS in ASD, it would be beneficial to include an additional caregiver-reported measure of social anxiety and self-reported measure of autism symptoms. Psychometric evaluation of the criterion measures in an ASD sample would also provide more compelling evidence for construct validity. While the present study does not identify whether the caregiver or adolescent is a more accurate or reliable reporter, use of clinical interviews and/or neurobiological measures may provide insight into this question in future research. Finally, as only the adolescent version of the SAS was evaluated, additional research on the child version would provide more convincing evidence for use of the SAS among children with ASD.

Taken together, the results of this study provide evidence that the SAS-A functions differently within a sample of youth with ASD compared with the literature standards for typically developing youth and that, within ASD, caregiver and adolescent reports differ in their psychometric properties. Such inconsistencies render them problematic for reporter comparisons at the scale and subscale levels. More broadly, these findings highlight the need for future work to evaluate the psychometric properties of measures used within an ASD sample. This pursuit is necessary for making valid inferences about the putative constructs that the measures are assumed to capture and to best understand, identify, and evaluate treatment of co-occurring symptoms within ASD.

\section{Acknowledgements}

The authors would like to thank the families for their participation in our research, as well as acknowledge the Marquette Autism Project undergraduate research team for their diligent work in the laboratory.

\section{Authors' Note}

Its contents are solely the responsibility of the authors and do not necessarily represent the official views of the National Institutes of Health.

\section{Declaration of Conflicting Interests}

The author(s) declared no potential conflicts of interest with respect to the research, authorship, and/or publication of this article.

\section{Funding}

The author(s) disclosed receipt of the following financial support for the research, authorship, and/or publication of this article: The authors would like to acknowledge grant support from the Autism Society of Southeastern Wisconsin (ASSEW), Marquette University, and the National Center for Advancing Translational Sciences, National Institutes of Health, through Grant Numbers KL2TR000056, UL1TR001436, and KL2TR001438. 


\section{References}

Aickin, M., Gensler, H. (1996). Adjusting for multiple testing when reporting research results: The Bonferroni vs Holm methods. American Journal of Public Health, 86, 726-728.

American Psychiatric Association . (2013). Diagnostic and statistical manual of mental disorders (5th ed.). Washington, DC: Author.

Angold, A., Costello, E. J., Messer, S. C., Pickles, A. (1995). Development of a short questionnaire for use in epidemiological studies of depression in children and adolescents. International Journal of Methods in Psychiatric Research, 5, 237-249.

Bellini, S. (2004). Social skill deficits and anxiety in high-functioning adolescents with autism spectrum disorders. Focus on Autism and Other Developmental Disabilities, 19, 78-86.

Bellini, S. (2006). The development of social anxiety in adolescents with autism spectrum disorders. Focus on Autism and Other Developmental Disabilities, 21, 138-145.

Birmaher, B., Khetarpal, S., Brent, D., Cully, M., Balach, L., Kaufman, J., Neer, S. M. (1997). The Screen for Child Anxiety Related Emotional Disorders (SCARED): Scale construction and psychometric characteristics. Journal of the American Academy of Child and Adolescent Psychiatry, 36, 545553.

Blakeley-Smith, A., Reaven, J., Ridge, K., Hepburn, S. (2012). Parent-child agreement of anxiety symptoms in youth with autism spectrum disorders. Research in Autism Spectrum Disorders, 6, 707-716.

Brady, E. U., Kendall, P. C. (1992). Comorbidity of anxiety and depression in children and adolescents. Psychological Bulletin, 111, 244-255.

Brown, E. J., Turovsky, J., Heimberg, R. G., Juster, H. R., Brown, T. A., Barlow, D. H. (1997). Validation of the Social Interaction Anxiety Scale and the Social Phobia Scale across the anxiety disorders. Psychological Assessment, 9, 21-27.

Browne, M. W., Cudeck, R. (1993). Alternative ways of assessing model fit. In Bollen, K. A., Long, J. S. (Eds.), Testing structural equation models (pp. 136-162). Newbury Park, CA: Sage.

Burnette, C. P., Mundy, P. C., Meyer, J. A., Sutton, S. K., Vaughan, A. E., Charak, D. (2005). Weak central coherence and its relations to theory of mind and anxiety in autism. Journal of Autism and Developmental Disorders, 35, 63-73.

Burrows, C. A., Usher, L. V., Becker-Haimes, E. M., McMahon, C. M., Mundy, P. C., Jensen-Doss, A., Henderson, H. A. (2018). Profiles and correlates of parent-child agreement on social anxiety symptoms in youth with autism spectrum disorder. Journal of Autism and Developmental Disorders, 48, 2023-2037.

Chang, Y.-C., Quan, J., Wood, J. J. (2012). Effects of anxiety disorder severity on social functioning in children with autism spectrum disorders. Journal of Developmental and Physical Disabilities, 24, 235-245.

Chevallier, C., Kohls, G., Troiani, V., Brodkin, E. S., Schultz, R. T. (2012). The social motivation theory of autism. Trends in Cognitive Sciences, 16, 231-239.

Comer, J. S., Kendall, P. C. (2004). A symptom-level examination of parent-child agreement in the diagnosis of anxious youths. Journal of the American Academy of Child and Adolescent Psychiatry, 43, 878-886.

Constantino, J. N., Davis, S. A., Todd, R. D., Schindler, M. K., Gross, M. M., Brophy, S. L., . . Reich, W. (2003). Validation of a brief quantitative measure of autistic traits: Comparison of the Social Responsiveness Scale with the Autism Diagnostic Interview-Revised. Journal of Autism and Developmental Disorders, 33, 427-433. 
Constantino, J. N., Gruber, C. P. (2005). Social Responsiveness Scale (SRS). Los Angeles, CA: Western Psychological Services.

Costello, E. J., Angold, A. (1988). Scales to assess child and adolescent depression: Checklists, screens, and nets. Journal of the American Academy of Child and Adolescent Psychiatry, 27, 726-737.

Cummings, C. M., Caporino, N. E., Kendall, P. C. (2014). Comorbidity of anxiety and depression in children and adolescents: 20 Years after. Psychological Bulletin, 140, 816-845.

De Los Reyes, A., Kazdin, A. E. (2005). Informant discrepancies in the assessment of childhood psychopathology: A critical review, theoretical framework, and recommendations for further study. Psychological Bulletin, 131, 483-509.

Duvekot, J., Ende, J., Verhulst, F. C., Greaves-Lord, K. (2017). Examining bidirectional effects between the autism spectrum disorder (ASD) core symptom domains and anxiety in children with ASD. Journal of Child Psychology and Psychiatry, 59, 277-284.

Factor, R. S., Ryan, S. M., Farley, J. P., Ollendick, T. H., Scarpa, A. (2017). Does the presence of anxiety and ADHD symptoms add to social impairment in children with autism spectrum disorder? Journal of Autism and Developmental Disorders, 47, 1122-1134.

Finch, H . (2006). Comparison of the performance of varimax and promax rotations: Factor structure recovery for dichotomous items. Journal of Educational Measurement, 43(1), 39-52.

García-López, L. J., Olivares, J., Hidalgo, M. D., Beidel, D. C., Turner, S. M. (2001). Psychometric properties of the social phobia and anxiety inventory, the Social Anxiety Scale for Adolescents, the Fear of Negative Evaluation Scale, and the Social Avoidance and Distress Scale in an adolescent Spanish-speaking sample. Journal of Psychopathology and Behavioral Assessment, 23, 51-59.

Hall-Lande, J. A., Eisenberg, M. E., Christenson, S. L., Neumark-Sztainer, D. (2007). Social isolation, psychological health, and protective factors in adolescence. Adolescence, 42(166), 265-286.

Henderson, H., Schwartz, C., Mundy, P., Burnette, C., Sutton, S., Zahka, N., Pradella, A. (2006). Response monitoring, the error-related negativity, and differences in social behavior in autism. Brain and Cognition, 61, 96-109.

Holm, S. (1979). A simple sequentially rejective multiple test procedure. Scandinavian Journal of Statistics, 6, 65-70.

$\mathrm{Hu}$, L., Bentler, P. M. (1999). Cutoff criteria for fit indexes in covariance structure analysis: Conventional criteria versus new alternatives. Structural Equation Modeling, 6, 1-55.

Hurtig, T., Kuusikko, S., Mattila, M.-L., Haapsamo, H., Ebeling, H., Jussila, K., . . Moilanen, I. (2009). Multi-informant reports of psychiatric symptoms among high-functioning adolescents with Asperger syndrome or autism. Autism, 13, 583-598.

Inderbitzen-Nolan, H. M., Walters, K. S. (2000). Social Anxiety Scale for adolescents: Normative data and further evidence of construct validity. Journal of Clinical Child Psychology, 29, 360-371.

Jitlina, K., Zumbo, B., Mirenda, P., Ford, L., Bennett, T., Georgiades, S., . . Duku, E. (2017). Psychometric properties of the Spence Children's Anxiety Scale: Parent report in children with autism spectrum disorder. Journal of Autism and Developmental Disorders, 47, 3847-3856.

Kaboski, J. R., Diehl, J. J., Beriont, J., Crowell, C. R., Villano, M., Wier, K., Tang, K. (2015). Brief report: A pilot summer robotics camp to reduce social anxiety and improve social/vocational skills in adolescents with ASD. Journal of Autism and Developmental Disorders, 45, 3862-3869. 
Kent, L., Vostanis, P., Feehan, C. (1997). Detection of major and minor depression in children and adolescents: Evaluation of the Mood and Feelings Questionnaire. Journal of Child Psychology and Psychiatry, 38, 565-573.

Kerns, C., Kendall, P. C., Berry, L., Souders, M. C., Franklin, M. E., Schultz, R. T., ... Herrington, J. (2014). Traditional and atypical presentations of anxiety in youth with autism spectrum disorder. Journal of Autism and Developmental Disorders, 44, 2851-2861.

Kerns, C. M., Renno, P., Kendall, P. C., Wood, J. J., Storch, E. A. (2017). Anxiety Disorders Interview Schedule-Autism addendum: Reliability and validity in children with autism spectrum disorder. Journal of Clinical Child and Adolescent Psychology, 46, 88-100.

Kerns, C. M., Rump, K., Worley, J., Kratz, H., McVey, A., Herrington, J., Miller, J. (2016). The differential diagnosis of anxiety disorders in cognitively-able youth with autism. Cognitive and Behavioral Practice, 23, 530-547.

Kuusikko, S., Pollock-Wurman, R., Jussila, K., Carter, A. S., Mattila, M.-L., Ebeling, H., . . .Moilanen, I. (2008). Social anxiety in high-functioning children and adolescents with autism and Asperger syndrome. Journal of Autism and Developmental Disorders, 38, 1697-1709.

La Greca, A. M., Dandes, S. K., Wick, P., Shaw, K., Stone, W. L. (1988). Development of the Social Anxiety Scale for Children: Reliability and concurrent validity. Journal of Clinical Child Psychology, 17, 84-91.

La Greca, A. M., Lopez, N. (1998). Social anxiety among adolescents: Linkages with peer relations and friendships. Journal of Abnormal Child Psychology, 26, 83-94.

La Greca, A. M., Stone, W. L. (1993). Social Anxiety Scale for Children-Revised: Factor structure and concurrent validity. Journal of Clinical Child Psychology, 22, 17-27.

Laugeson, E., Ellingsen, R., Tucci, L. C., Bolourian, Y., Bates, S. (2015). Using parent-assistance and teacher-facilitation to teach social skills in the classroom: Treatment outcome for the PEERS ${ }^{\circledR}$ school-based curriculum. Retrieved from https://imfar.confex.com/imfar/2015/webprogram/Paper19151.html

Laugeson, E. A., Frankel, F., Gantman, A., Dillon, A. R., Mogil, C. (2012). Evidence-based social skills training for adolescents with autism spectrum disorders: The UCLA PEERS program. Journal of Autism and Developmental Disorders, 42, 1025-1036.

Lee, I. A., Preacher, K. J. (2013). Calculation for the test of the difference between two dependent correlations with one variable in common [Computer software]. Retrieved from http://quantpsy.org

Leyfer, O. T., Folstein, S. E., Bacalman, S., Davis, N. O., Dinh, E., Morgan, J., . . . Lainhart, J. E. (2006). Comorbid psychiatric disorders in children with autism: Interview development and rates of disorders. Journal of Autism and Developmental Disorders, 36, 849-861.

Liu, Y., Millsap, R. E., West, S. G., Tein, J.-Y., Tanaka, R., Grimm, K. J. (2017). Testing measurement invariance in longitudinal data with ordered-categorical measures. Psychological Methods, 22, 486-506.

Lopata, C., Toomey, J. A., Fox, J. D., Volker, M. A., Chow, S. Y., Thomeer, M. L., . . Smerbeck, A. M. (2010). Anxiety and depression in children with HFASDs: Symptom levels and source differences. Journal of Abnormal Child Psychology, 38, 765-776.

Lord, C., Rutter, M., DiLavore, P. C., Risi, S., Gotham, K., Bishop, S. L. (2001). Autism Diagnostic Observation Schedule (ADOS). Los Angeles: Western Psychological Services.

Magiati, I., Chan, J. Y., Tan, W.-L. J., Poon, K. K. (2014). Do non-referred young people with autism spectrum disorders and their caregivers agree when reporting anxiety symptoms? A 
preliminary investigation using the Spence Children's Anxiety Scale. Research in Autism Spectrum Disorders, 8, 546-558.

March, J. S. (2013). Multidimensional Anxiety Scale for Children (2nd ed.). Toronto, Ontario, Canada: Multi-Health Systems.

Mattick, R. P., Clarke, J. C. (1998). Development and validation of measures of social phobia scrutiny fear and social interaction anxiety. Behaviour Research and Therapy, 36, 455-470.

May, T., Cornish, K., Rinehart, N. J. (2015). Parent-child agreement using the Spence Children's Anxiety Scale and a thermometer in children with autism spectrum disorder. Autism Research and Treatment, 2015, 315495. doi:10.1155/2015/315495

Mayes, S. D., Calhoun, S. L., Murray, M. J., Zahid, J. (2011). Variables associated with anxiety and depression in children with autism. Journal of Developmental and Physical Disabilities, 23, 325-337.

Mazefsky, C. A., Kao, J., Oswald, D. P. (2011). Preliminary evidence suggesting caution in the use of psychiatric self-report measures with adolescents with high-functioning autism spectrum disorders. Research in Autism Spectrum Disorders, 5, 164-174.

McPartland, J. C., Crowley, M. J., Perszyk, D. R., Mukerji, C. E., Naples, A. J., Wu, J., Mayes, L. C. (2012). Preserved reward outcome processing in ASD as revealed by event-related potentials. Journal of Neurodevelopmental Disorders, 4(1), 16. doi:10.1186/1866-1955-4-16

McVey, A. J., Schiltz, H. K., Haendel, A. D., Dolan, B. K., Willar, K. S., Pleiss, S. S., . . Murphy, C. C. (2018). Social difficulties in youth with autism with and without anxiety and ADHD symptoms. Autism Research, 11, 1679-1689.

Meyer, J. A., Mundy, P. C., Van Hecke, A. V., Durocher, J. S. (2006). Social attribution processes and comorbid psychiatric symptoms in children with Asperger syndrome. Autism, 10, 383-402.

Muthén, L. K., Muthén, B. O. (1998-2012). Mplus user's guide (7th ed.). Los Angeles, CA: Muthén \& Muthén.

Myers, M. G., Stein, M. B., Aarons, G. A. (2002). Cross validation of the Social Anxiety Scale for Adolescents in a high school sample. Journal of Anxiety Disorders, 16, 221-232.

Olino, T. M., Finsaas, M., Dougherty, L. R., Klein, D. N. (2018). Is parent-child disagreement on child anxiety explained by differences in measurement properties? An examination of measurement invariance across informants and time. Frontiers in Psychology, 9, 1295. doi:10.3389/fpsyg.2018.01295

Ooi, Y. P., Weng, S.-J., Magiati, I., Ang, R. P., Goh, T. J., Fung, D. S., Sung, M. (2016). Factors influencing agreement between parent and child reports of anxiety symptoms among children with high-functioning autism spectrum disorders. Journal of Developmental and Physical Disabilities, 28, 407-424.

Patel, S., Day, T. N., Jones, N., Mazefsky, C. A. (2017). Association between anger rumination and autism symptom severity, depression symptoms, aggression, and general dysregulation in adolescents with autism spectrum disorder. Autism, 21, 181-189.

Pugliese, C. E., Fritz, M. S., White, S. W. (2015). The role of anger rumination and autism spectrum disorder-linked perseveration in the experience of aggression in the general population. Autism, 19, 704-712.

Rodebaugh, T. L., Woods, C. M., Heimberg, R. G., Liebowitz, M. R., Schneier, F. R. (2006). The factor structure and screening utility of the Social Interaction Anxiety Scale. Psychological Assessment, 18, 231-237. 
Rodgers, J., Wigham, S., McConachie, H., Freeston, M., Honey, E., Parr, J. R. (2016). Development of the anxiety scale for children with autism spectrum disorder (ASC-ASD). Autism Research, 9, 1205-1215.

Schiltz, H., Mclntyre, N., Swain-Lerro, L., Zajic, M., Mundy, P. (2017). The stability of self-reported anxiety in youth with autism versus ADHD or typical development. Journal of Autism and Developmental Disorders, 47, 3756-3764.

Schohl, K. A., Van Hecke, A. V., Carson, A. M., Dolan, B., Karst, J., Stevens, S. (2014). A replication and extension of the PEERS intervention: Examining effects on social skills and social anxiety in adolescents with autism spectrum disorders. Journal of Autism and Developmental Disorders, 44, 532-545.

Sharp, C., Goodyer, I. M., Croudace, T. J. (2006). The Short Mood and Feelings Questionnaire (SMFQ): A unidimensional item response theory and categorical data factor analysis of self-report ratings from a community sample of 7-through 11-year-old children. Journal of Abnormal Child Psychology, 34, 365-377.

Spence, S. H. (1998). A measure of anxiety symptoms among children. Behaviour Research and Therapy, 36, 545-566.

Sterling, L., Dawson, G., Estes, A., Greenson, J. (2008). Characteristics associated with presence of depressive symptoms in adults with autism spectrum disorder. Journal of Autism and Developmental Disorders, 38, 1011-1018.

Storch, E. A., Masia-Warner, C., Dent, H. C., Roberti, J. W., Fisher, P. H. (2004). Psychometric evaluation of the Social Anxiety Scale for Adolescents and the Social Phobia and Anxiety Inventory for Children: Construct validity and normative data. Journal of Anxiety Disorders, $18,665-679$.

Stratis, E. A., Lecavalier, L. (2015). Informant agreement for youth with autism spectrum disorder or intellectual disability: A meta-analysis. Journal of Autism and Developmental Disorders, 45, 1026-1041.

Sutton, S. K., Burnette, C. P., Mundy, P. C., Meyer, J., Vaughan, A., Sanders, C., Yale, M. (2005). Resting cortical brain activity and social behavior in higher functioning children with autism. Journal of Child Psychology and Psychiatry, 46, 211-222.

Swain, D., Scarpa, A., White, S., Laugeson, E. (2015). Emotion dysregulation and anxiety in adults with ASD: Does social motivation play a role? Journal of Autism and Developmental Disorders, 45, 3971-3977.

Thapar, A., McGuffin, P. (1998). Validity of the shortened Mood and Feelings Questionnaire in a community sample of children and adolescents: A preliminary research note. Psychiatry Research, 81, 259-268.

Uljarević, M., Hamilton, A. (2013). Recognition of emotions in autism: A formal meta-analysis. Journal of Autism and Developmental Disorders, 43, 1517-1526.

Uljarević, M., Richdale, A. L., McConachie, H., Hedley, D., Cai, R. Y., Merrick, H., . . Le Couteur, A. (2017). The Hospital Anxiety and Depression Scale: Factor structure and psychometric properties in older adolescents and young adults with autism spectrum disorder. Autism Research, 11, 258-269.

Ung, D., McBride, N., Collier, A., Selles, R., Small, B., Phares, V., Storch, E. (2016). The relationship between peer victimization and the psychological characteristics of youth with autism spectrum disorder. Research in Autism Spectrum Disorders, 32, 70-79. 
Usher, L. V, Burrows, C. A., Schwartz, C. B., Henderson, H. A. (2015). Social competence with an unfamiliar peer in children and adolescents with high functioning autism: Measurement and individual differences. Research in Autism Spectrum Disorders, 17, 25-39.

Van Roekel, E., Scholte, R. H. J., Didden, R. (2010). Bullying among adolescents with autism spectrum disorders: Prevalence and perception. Journal of Autism and Developmental Disorders, 40, 63-73.

van Steensel, F. J. A., Bögels, S. M., Perrin, S. (2011). Anxiety disorders in children and adolescents with autistic spectrum disorders: A meta-analysis. Clinical Child and Family Psychology Review, 14, 302-317. Retrieved from http://www.ncbi.nIm.nih.gov/pmc/articles/PMC3162631/pdf/10567 2011 Article 97.p df

van Steensel, F. J. A., Heeman, E. J. (2017). Anxiety levels in children with autism spectrum disorder: A meta-analysis. Journal of Child and Family Studies, 26, 1753-1767.

Watson, D., Friend, R. (1969). Measurement of social-evaluative anxiety. Journal of Consulting and Clinical Psychology, 33, 448-457.

White, S. W., Bray, B. C., Ollendick, T. H. (2012). Examining shared and unique aspects of social anxiety disorder and autism spectrum disorder using factor analysis. Journal of Autism and Developmental Disorders, 42, 874-884.

White, S. W., Lerner, M. D., McLeod, B. D., Wood, J. J., Ginsburg, G. S., Kerns, C., ... Walkup, J. (2015). Anxiety in youth with and without autism spectrum disorder: Examination of factorial equivalence. Behavior Therapy, 46, 40-53.

White, S. W., Oswald, D., Ollendick, T., Scahill, L. (2009). Anxiety in children and adolescents with autism spectrum disorders. Clinical Psychology Review, 29, 216-229. Retrieved from http://www.ncbi.nlm.nih.gov/pmc/articles/PMC2692135/pdf/nihms113987.pdf

White, S. W., Roberson-Nay, R. (2009). Anxiety, social deficits, and loneliness in youth with autism spectrum disorders. Journal of Autism and Developmental Disorders, 39, 1006-1013.

White, S. W., Scarpa, A., Conner, C. M., Maddox, B. B., Bonete, S. (2015). Evaluating change in social skills in high-functioning adults with autism spectrum disorder using a laboratory-based observational measure. Focus on Autism and Other Developmental Disabilities, 30, 3-12.

White, S. W., Schry, A. R., Maddox, B. B. (2012). Brief report: The assessment of anxiety in highfunctioning adolescents with autism spectrum disorder. Journal of Autism and Developmental Disorders, 42, 1138-1145.

Williams, D. (2010). Theory of own mind in autism: Evidence of a specific deficit in selfawareness? Autism, 14, 474-494.

Wood, J. J., Gadow, K. D. (2010). Exploring the nature and function of anxiety in youth with autism spectrum disorders. Clinical Psychology: Science and Practice, 17, 281-292.

Zablotsky, B., Black, L. I., Maenner, M. J., Schieve, L. A., Blumberg, S. J. (2015). Estimated prevalence of autism and other developmental disabilities following questionnaire changes in the 2014 National Health Interview Survey. National Health Statistics Reports, 87, 1-20. 